\title{
Estratégias das empresas farmacêuticas para acumulação de capital e os efeitos no acesso a medicamentos
}

Carolinne Thays SCOPEL: Escola Nacional de Saúde Pública Sérgio Arouca - Ensp, Fundação Oswaldo Cruz - Fiocruz. ORCID: https://orcid.org/0000-0003-3254-2800

Maria Auxiliadora OLIVEIRA: Escola Nacional de Saúde Pública Sérgio Arouca - Ensp, Fundação Oswaldo Cruz - Fiocruz. ORCID: https://orcid.org/0000-0003-2400-536X

Artur Monte CARDOSO: Instituto de Estudos em Saúde Coletiva - IESC, Universidade Federal do Rio de Janeiro - UFRJ. ORCID: http://orcid.org/0000-0001-9658-5899

\section{Resumo}

Ao longo do desenvolvimento das suas trajetórias tecnológicas, as empresas farmacêuticas utilizaram um conjunto diversificado de estratégias empresariais para se consolidarem, crescerem e acumularem capital. O mercado farmacêutico mundial é dominado por empresas transnacionais, concentrado por classes terapêuticas, oligopolizado por empresas líderes, marcado pela proteção patentária na extensão de monopólios e pela fidelidade a marcas. A contínua expansão desse mercado utiliza a manutenção dessas características, mas também reinventa novas estratégias de acumulação de capital. Essas estratégias empresariais produzem efeitos sobre o acesso aos medicamentos. Por isso, entender o funcionamento delas e seus efeitos sobre o acesso a medicamentos pode trazer subsídios para o enfrentamento delas em âmbito nacional ou internacional e para a garantia do acesso aos medicamentos no nível local. O objetivo desse artigo é identificar, descrever e categorizar as estratégias empresariais utilizadas no setor farmacêutico, além de identificar barreiras no acesso a medicamentos constituídas por essas estratégias. É um estudo exploratório, constituído pelas seguintes etapas metodológicas: revisão não exaustiva da literatura, identificação e descrição das estratégias utilizadas pelas empresas farmacêuticas e discussão dos efeitos das estratégias sobre o acesso a medicamentos. Foram mapeadas 23 estratégias, agrupadas em sete tipos de estratégias. A partir da identificação das estratégias empresariais, foram propostas definições para cada uma. Os tipos de estratégias empresariais identificados são: inovativas, de rearranjo da forma

Recebido: 12 out. 2020 Aceito: 21 out. 2020

Autor de correspondência: Carolinne Scopel carol.thays@gmail.com

Conflito de interesses: Os autores declaram não haver nenhum interesse profissional ou pessoal que possa gerar conflito de interesses em relação a este manuscrito. empresarial, patentárias, de busca de novos mercados, de acesso, de capital fictício e mercadológicas. Investimento em inovações: investimento na inovação tecnológica e na formação do conhecimento tácito dentro da empresa, produzindo uma trajetória tecnológica. Fusão: duas empresas separadas se consolidam em uma organização conjunta e ações são emitidas com o nome da nova identidade comercial. Aquisição: uma empresa menor é consumida por outra, geralmente requer grandes quantias de dinheiro, tende a ser hostil e com conotação negativa. Takeover: uma empresa, de forma hostil, assume o controle de outra sem o consentimento da empresa adquirida, geralmente envolve uma empresa maior que visa uma menor. Troca de ativos: troca de ativos entre duas empresas, sem alterar a forma organizativa das empresas. Carve-out: uma empresa vende uma participação acionária de um segmento de seus negócios, que pode não fazer parte de suas operações principais, para se beneficiar da entrada imediata de fluxo de caixa, mantendo um patrimônio líquido. Spinoff: uma empresa vende toda unidade de negócios diretamente para outra empresa, criando uma entidade separada. Joint venture: colaboração comercial ou tecnológica, na qual duas ou mais empresas acordam em reunir seus recursos, propriedades e conhecimentos para realizar uma tarefa específica, com retornos e riscos compartilhados. Aliança estratégica: parcerias estratégicas entre empresas para trazem avanços para a P\&D e proporcionar retornos financeiros sobre os produtos 
desenvolvidos, geralmente envolve pelo menos uma empresa farmacêutica estabelecida. Licenciamento de tecnologias: concessão permissão para uma empresa desenvolver compostos específicos inicialmente pesquisados por outras empresas. Monopólio patentário: depósito de pedido de patente nos escritórios de cada país a fim de obter uma situação de monopólio pela concessão ou expectativa de concessão de uma patente, restringindo a produção, a comercialização e a concorrência de produtos. Evergreening: prática de extensão do monopólio patentário, pela extensão do tempo de análise dos pedidos de patente ou pela sobreposição de pedidos de patente para um único produto. Litígio sobre patentes: inúmeros recursos administrativos ou via judicial, que causam extensões do tempo de análise de pedidos de patente. Reposicionamento no mercado: empresas encerram a produção e deixam o mercado mundial ou reposicionam-se no mercado, devido ao retorno financeiro ser pequeno ou não valer a pena a produção de determinados produtos sem proteção patentária, para mercados de países em desenvolvimento ou para uma população restrita. Mercado de genéricos: entrada no mercado de medicamentos sintéticos genéricos, geralmente após a expiração da patente. Mercado de biossimilares: entrada no mercado de medicamentos biológicos genéricos, geralmente após a expiração da patente. Diferenciação de preços: oferta de medicamentos a preços menores para países de renda média e baixa, a partir da segmentação do mercado de acordo com a suposta capacidade de pagar. Acesso expandido: uma das formas de disponibilização de um medicamento novo e promissor, antes do produto ser aprovado pelas agências reguladoras e ser lançado no mercado, em caso de doenças graves, ameaça à vida ou falta de alternativa terapêutica satisfatória. Mercado financeiro: uso dos lucros das empresas para reinvestir no mercado financeiro. Recompra de ações: uso dos lucros das empresas para recompra das suas próprias ações com o propósito de dar impulsos manipulados nos preços das ações e gerar lucros em escala massiva. Capital de risco: compra, geralmente não negociada publicamente, de uma participação minoritária de uma empresa iniciante por outra empresa estabelecida. Adoção de blockbuster: adoção de produto com faturamento acima de US\$ 1 bilhão por ano, garantido pela exclusividade do monopólio patentário e pelo marketing. Aposta em marcas e marketing: introdução de um produto no mercado por meio de uma marca e uso de estratégias de marketing para sua promoção. As estratégias empresariais descritas influenciam o acesso a medicamentos e podem constituir barreiras ao mesmo. É importante aprofundar o entendimento sobre quais dimensões do acesso são restringidas pelas estratégias das empresas transnacionais farmacêuticas e como isso ocorre, já que nem todas as dimensões do acesso são influenciadas dessa forma. É possível identificar alguns efeitos no acesso a medicamentos: aumento dos preços dos medicamentos, redução da disponibilidade de medicamentos e desabastecimento, restrições de circulação decorrentes da barreira patentária, redução dos produtores e da concorrência, alterações sanitárias e diminuição da qualidade dos produtos. A sistematização das estratégias empresariais contribui para a compreensão desse universo, formulação política e futuros estudos que avancem no detalhamento do seu funcionamento e suas implicações para o acesso a medicamentos. Essa contribuição não pretende ser estanque, mas é um ponto de partida a continuação dessa linha de investigação.

Descritores: Indústria Farmacêutica; Acesso a Medicamentos Essenciais e Tecnologias em Saúde; Assistência à Saúde.

Keywords: Drug Industry; Access to Essential Medicines and Health Technologies; Delivery of Health Care.

Palabras-claves: Industria Farmacéutica; Acceso a Medicamentos Esenciales y Tecnologías Sanitarias; Prestación de Atención de Salud. 